\title{
Regional Blood Flows in Newborn Lambs During Endotracheal Continuous Airway Pressure and Continuous Negative Pressure Breathing
}

\author{
JAIME A. FURZAN, GEORGIO GABRIELE, JAMES M. WHEELER, DAVID E. FIXLER, AND \\ CHARLES R. ROSENFELD ${ }^{(32)}$
}

Southwestern Medical School, Dallas, Texas, USA

\begin{abstract}
Summary
Cardiovascular changes resulting from continuous distending alveolar pressure during endotracheal intubation (CPAP) and continuous negative pressure (CNP) were studied in two groups of healthy newborn lambs at 6 and $11 \mathrm{~mm} \mathrm{Hg}$ and -6 and $-11 \mathrm{~mm}$ $\mathrm{Hg}$, respectively. Heart rate, left ventricular pressure, and arterial blood gases were unchanged in each group. Cardiac output decreased 16 and $15 \%$ at 6 and $11 \mathrm{~mm} \mathrm{Hg}$ CPAP $(P<0.05)$, respectively, whereas a fall of $9 \%$ occurred at both -6 and -11 $\mathrm{mm} \mathrm{Hg} \mathrm{CNP}(P>0.05)$. Central venous pressure $(\mathrm{mm} \mathrm{Hg})$ rose from a control value of $7.0 \pm 1.4$ (mean \pm S.E.) to $11 \pm 3.1$ and 12 \pm 2.7 at 6 and $11 \mathrm{~mm} \mathrm{Hg}$ CPAP $(P<0.025)$, respectively, and decreased from a control of $7.7 \pm 0.7$ to $5.8 \pm 0.5$ at $-6 \mathrm{~mm} \mathrm{Hg}$ $\mathrm{CNP}$ and $4.8 \pm 1.3$ at $-11 \mathrm{~mm} \mathrm{Hg} \mathrm{CNP}(P<0.05)$. Jugular venous pressure also rose progressively with increasing CPAP $(P$ $<0.05$ ), but was unchanged during CNP. Regional blood flow to the liver fell at both 6 and $11 \mathrm{~mm} \mathrm{Hg} \mathrm{CPAP,} \mathrm{whereas} \mathrm{renal} \mathrm{and}$ gastrointestinal blood flows showed a tendency to decrease at 11 $\mathrm{mm} \mathrm{Hg}$ CPAP. The removal of CPAP resulted in a prompt return of venous pressure, cardiac output, and regional blood flows to control values. Reductions in blood flows to the gastrointestinal tract at $-6 \mathrm{~mm} \mathrm{Hg} \mathrm{CNP}$ and spleen at $-11 \mathrm{~mm} \mathrm{Hg} \mathrm{CNP}$ were observed; blood flows returned toward control values when CNP was removed.
\end{abstract}

\section{Speculation}

The application of continuous distending airway pressure may have potentially deleterious effects on the cardiovascular system of infants with normal or improving lung compliance. The increase in venous pressures that occurs may contribute to the development of intracranial hemorrhage in the neonate.

Continuous distending alveolar pressure by either continuous positive airway pressure (CPAP) $(7,10)$ or continuous extrathoracic negative pressure (CNP) $(4,29)$ has been used in the management of newborn infants with pulmonary and extrapulmonary disorders. Despite the wide use of these modes of ventilatory assistance, our understanding of their effects on the newborn cardiovascular system with different degrees of lung compliance is incomplete. Various investigators have reported alterations in cardiac output and other hemodynamic variables such as heart rate, arterial blood pressure, and central venous pressure during both CPAP $(9,15,17,19,21,30,31)$ and $\operatorname{CNP}(3,4,17,19,26)$ but none have investigated the simultaneous changes in cardiac output and organ blood flows, nor have studies been done in newborn animals. Using the radionuclide-labeled microsphere technique, we recently have shown that significant increases in venous pressures and decreases in cardiac output and blood flows to the choroid-retina and kidneys occur during the application of head-box CPAP in newborn lambs (8). To determine whether similar changes occur with CPAP delivered by endotracheal tube and CNP, we have studied the effects of these ventilatory techniques in newborn lambs with normal lungs.

\section{MATERIALS AND METHODS}

Two groups of lambs were studied. The first group was studied during endotracheal CPAP and consisted of eight spontaneously delivered healthy newborn lambs that weighed 2.9 to $6.0 \mathrm{~kg}$ and were 3 to 8 days of age at the time of study. The second group was studied during CNP and included eight spontaneously delivered healthy newborn lambs that weighed 2.8 to $7.2 \mathrm{~kg}$ and were 2 to 7 days old at the time of study. The lambs were lightly sedated at the time of study with intramuscular chloral hydrate, $100 \mathrm{mg} / \mathrm{kg}$, and restrained in the supine position. Polyvinyl catheters $(0.75$ $\mathrm{mm}$ inside diameter $\times 1.2 \mathrm{~mm}$ outside diameter) were placed in both femoral arteries to a level of the internal iliac arteries, the cephalic portion of the right external jugular vein, and the superior vena cava via the right external jugular vein (8). Another catheter $(0.99 \mathrm{~mm}$ inside diameter $\times 1.36 \mathrm{~mm}$ outside diameter $)$ was passed to the apex of the left ventricle via the right carotid artery, which was ligated distally. The ventricular location of this catheter was identified by pressure tracings recorded on a six-channel Dynograph Recorder (model RM). The location of the catheter tips was confirmed at postmortem in all animals.

The animals in the first group were intubated orally after placement of the catheters, and the endotracheal tube was secured. CPAP was administered with the system described by Gregory et al. (10), monitoring the application of pressure with an aneroid manometer and controlling the level of pressure applied by occlusion of a reservoir bag with an open tail piece and screw clamp. The flow rate in the system varied from 5 to 10 liters/min. To eliminate effects resulting from a specific sequence change, airway pressure was varied so that one-half of the animals were studied at $0,6,11$, and $0 \mathrm{~mm} \mathrm{Hg}$, and the other one-half were studied at $0,11,6$, and $0 \mathrm{~mm} \mathrm{Hg}$. The use of two control periods helps to provide evidence of stability of the animal preparation. Lambs in the second group were studied in a modified negative pressure respirator ${ }^{1}$ consisting of two compartments, a body compartment connected to a motor-driven vacuum pump and a head compartment separated from the former by a diaphragm that fitted snugly around the neck of the animals. A continuous negative chest wall pressure of either -6 or $-11 \mathrm{~mm} \mathrm{Hg}$ was applied in a random fashion so that the animals were studied in the manner described for CPAP. Both groups of animals were breathing spontaneously room air throughout the studies.

Because it is the clinical practice to wait 15 to $20 \mathrm{~min}$ after a change in CPAP or CNP before obtaining arterial blood gas determinations, a 15-min period was allowed for stabilization after each pressure change. Heart rate, systolic left ventricular pressure, mean cephalic jugular venous pressure (JVP), and mean central

Isolette Incubator-Respirator; Air Shield, Ltd, Hatboro, PA. 
Table 1. Hemodynamic changes during the application of continuous airway pressure breathing by endotracheal tube

\begin{tabular}{|c|c|c|c|c|}
\hline & \multicolumn{4}{|c|}{ Airway pressure (mm Hg) } \\
\hline & 0 & 6 & 11 & 0 \\
\hline Heart rate (bpm) & $205 \pm 27^{1}$ & $235 \pm 17$ & $226 \pm 29$ & $247 \pm 14$ \\
\hline Left ventricular pressure ( $\mathrm{mm} \mathrm{Hg}$ ) & $99 \pm 5.7$ & $101 \pm 4.0$ & $101 \pm 4.7$ & $109 \pm 4.0$ \\
\hline Cardiac output $(\mathrm{ml} / \mathrm{min} \cdot \mathrm{kg})$ & $248 \pm 22$ & $206 \pm 11^{2}$ & $202 \pm 15^{2}$ & $234 \pm 24$ \\
\hline CVP (mm Hg) & $7.00 \pm 1.41$ & $10.9 \pm 3.14^{2}$ & $12.0 \pm 2.69^{2}$ & $7.51 \pm 1.83$ \\
\hline JVP (mm Hg) & $11.5 \pm 1.78$ & $13.9 \pm 2.13$ & $15.3 \pm 2.19^{2}$ & $12.9 \pm 2.38$ \\
\hline $\mathrm{PaO}_{2}(\mathrm{~mm} \mathrm{Hg})$ & $80.8 \pm 5.45$ & $84.8 \pm 1.66$ & $81.8 \pm 4.86$ & $86.8 \pm 3.16$ \\
\hline $\mathrm{PaCO}_{2}(\mathrm{~mm} \mathrm{Hg})$ & $31.9 \pm 0.89$ & $30.4 \pm 1.86$ & $32.4 \pm 1.84$ & $30.0 \pm 1.25$ \\
\hline $\mathrm{pHa}$ & $7.34 \pm 0.02$ & $7.36 \pm 0.03$ & $7.34 \pm 0.03$ & $7.40 \pm 0.02$ \\
\hline
\end{tabular}

${ }^{1}$ Mean \pm S.E. There are eight measurements at each pressure setting.

${ }^{2}$ Different from initial control values; $P<0.05$.

Table 2. Organ blood flow ( $\mathrm{ml} / \mathrm{min} \cdot \mathrm{g})$ during the application of continuous airway pressure breathing by endotracheal tube

Airway pressure $(\mathrm{mm} \mathrm{Hg})$

\begin{tabular}{|c|c|c|c|c|}
\hline & \\
\hline & 0 & 6 & 11 & 0 \\
\hline Renal & $1.62 \pm 0.20^{1}$ & $1.71 \pm 0.22$ & $1.40 \pm 0.17^{2}$ & $1.46 \pm 0.13$ \\
\hline Gastrointestinal tract & $0.76 \pm 0.10$ & $0.90 \pm 0.10$ & $0.65 \pm 0.05^{2}$ & $0.89 \pm 0.10$ \\
\hline Liver & $0.66 \pm 0.25$ & $0.27 \pm 0.06^{3}$ & $0.31 \pm 0.08^{3}$ & $0.36 \pm 0.10$ \\
\hline Spleen & $2.17 \pm 0.43$ & $1.99 \pm 0.41$ & $2.00 \pm 0.42$ & $1.81 \pm 0.31$ \\
\hline Heart & $1.42 \pm 0.20$ & $1.76 \pm 0.16$ & $1.69 \pm 0.15$ & $1.91 \pm 0.21$ \\
\hline Head & $0.24 \pm 0.04$ & $0.21 \pm 0.03$ & $0.17 \pm 0.03$ & $0.25 \pm 0.04$ \\
\hline Brain & $0.99 \pm 0.16$ & $0.87 \pm 0.10$ & $0.87 \pm 0.12$ & $0.79 \pm 0.08$ \\
\hline Left eye & $2.44 \pm 0.64$ & $2.07 \pm 0.22$ & $1.97 \pm 0.28$ & $2.71 \pm 0.78$ \\
\hline
\end{tabular}

${ }^{1}$ Mean \pm S.E. There are eight measurements at each pressure setting.

${ }^{2}$ Different from value at $6 \mathrm{~mm} \mathrm{Hg} ; P<0.05$

${ }^{3}$ Different from initial control value; $P<0.05$.

venous pressure (CVP) were continuously recorded during the stabilization period (Dynograph Recorder model RM). Arterial blood samples were obtained before and $15 \mathrm{~min}$ after each pressure change. After stabilization at each pressure setting, $25 \pm 5 \mu \mathrm{m}$ (mean \pm S.D.) diameter microspheres (Minnesota Mining and Manufacturing Co., St. Paul, MN) labeled with either ${ }^{125}$ Iodine, ${ }^{46}$ Scandium, ${ }^{141}$ Cerium, or ${ }^{85}$ Strontium were infused into the left ventricle. The infusion sequence of the isotopes was randomly assigned. The method for the infusion and analysis of microspheres has been described in detail (25). Starting just before the microsphere infusion, samples were simultaneously withdrawn into counting vials under oil from both femoral artery catheters and the jugular venous catheter by a four-channel Harvard pump at a rate of $2.06 \mathrm{ml} / \mathrm{min}$ for $3 \mathrm{~min}$. The disintegrations per minute in the arterial reference samples were determined and used for the calculation of cardiac output and regional blood flows, whereas the jugular venous samples were used to evaluate the magnitude of cephalic arteriovenous shunting of microspheres. Cardiac output, organ blood flows, and cephalic arteriovenous shunting were calculated as previously described (8).

Changes in intraesophageal pressure were monitored continuously in two lambs in the CPAP study and in five lambs in the CNP study. A latex esophageal balloon, $4 \mathrm{~cm}$ long and with linear responses over the range of pressures measured, was positioned in mid-esophagus and filled with $0.5 \mathrm{ml}$ of air. The average intraesophageal pressure was determined at each level of pressure and is reported as the percentage of change from the initial control and the percentage of airway pressure transmitted. The latter was calculated as the ratio of the change in intra-esophageal pressure to the level of CPAP or CNP applied times 100.

The lambs were killed at the end of each experiment with the injection of a saturated $\mathrm{KCl}$ solution into the left ventricle and immediately dissected for tissue preparation. The following organs were removed and weighed: brain, eyes, heart, liver, spleen, kidneys, and gastrointestinal tract. In the CNP group, adrenal glands and thyroid were also removed. Tissues and organs were placed directly into preweighed counting vials or, in the case of larger organs (e.g., liver, spleen, and heart), were ground, and aliquots of these organs were placed into preweighed vials (25). The left eye was prepared for counting by removing the vitrous body, lens, cornea, iris, conjuctiva, and any attached muscle (8). The remaining choroid-retina was then placed into the preweighed counting vial. Samples were counted in a three-channel Auto-Gamma Spectrometer System (model 5375). ${ }^{2}$

Statistical analysis was performed using repeated measured analysis of variance followed by Student Newman-Keuls multiple comparison procedure. Nonpaired $t$ test was used to compare baseline data from the two groups of lambs. Reported differences were considered significant at the $5 \%$ level. All mean values are reported as \pm S.E.

\section{RESULTS}

The baseline data from the two groups of newborn lambs have been compared to determine if the animals were similar, thereby permitting us to compare the results obtained. Although the weights of the lambs at the time of study were similar, $4.2 \pm 0.5$ $\mathrm{kg}$ in the CPAP group and $4.0 \pm 0.5 \mathrm{~kg}$ in the CNP group, the former group were slightly older, $5.6 \pm 0.6$ days ( 3 to 8 days) versus $3.8 \pm 0.5$ days $(2$ to 7 days $)$, respectively $(P<0.05)$. Other baseline values obtained during the initial control period for both groups of lambs are presented in Tables 1 to 4 . Arterial blood gases and $\mathrm{pH}$ were normal in each group, indicating apparently normal ventilatory and acid-base balance. There was no statistical difference in cardiac output, heart rate, left ventricular pressure, central venous pressure, and the majority of organ blood flows. However, there were significant differences, $P<0.05$, in blood flows to the gastrointestinal tract, heart, and spleen, and in jugular venous pressure. These values were higher in the CNP group of animals in each instance. No significant differences were observed between the sequences of application of either endotracheal-CPAP or CNP. We, therefore, have grouped the data from each study

\footnotetext{
${ }^{2}$ Packard Instruments Co., Downers Grove, IL.
} 
Table 3. Hemodynamic changes during the application of continuous negative pressure breathing

\begin{tabular}{|c|c|c|c|c|}
\hline & & Negative ches & sure $(\mathrm{mm} \mathrm{Hg})$ & \\
\hline Heart rate $(\mathrm{bpm})$ & $260 \pm 9.1^{1}$ & $261 \pm 8.3$ & $273 \pm 10$ & $265 \pm 9.8$ \\
\hline Cardiac output $(\mathrm{ml} / \mathrm{min} \cdot \mathrm{kg})$ & $302 \pm 21$ & $272 \pm 22$ & $281 \pm 33$ & $373 \pm 23^{2}$ \\
\hline $\mathrm{CVP}(\mathrm{mm} \mathrm{Hg})$ & $7.7 \pm 0.70$ & $5.8 \pm 0.54$ & $4.8 \pm 1.31^{2}$ & $7.5 \pm 0.91$ \\
\hline JVP (mm Hg) & $15.8 \pm 0.81$ & $13.5 \pm 2.09$ & $15.6 \pm 1.48$ & $16 \pm 1.13$ \\
\hline $\mathrm{pHa}$ & $7.40 \pm 0.02$ & $7.38 \pm 0.02$ & $7.35 \pm 0.02$ & $7.41 \pm 0.01$ \\
\hline
\end{tabular}

${ }^{1}$ Mean \pm S.E. There are eight measurements at each pressure setting.

${ }^{2}$ Different from initial control value; $P<0.05$.

Table 4. Organ blood flows $(\mathrm{ml} / \mathrm{min} \cdot \mathrm{g})$ during the application of continuous negative pressure breathing

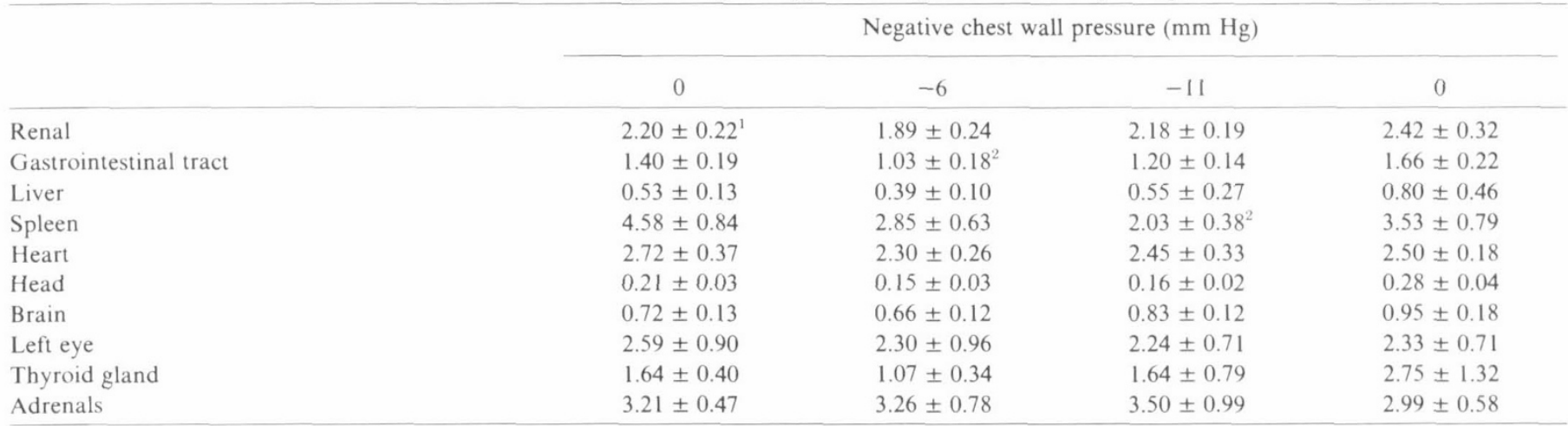

${ }^{1}$ Mean \pm S.E. There are eight measurements at each pressure setting.

Different from initial control value; $P<0.05$.

and evaluated them by comparing all measurements obtained at 6 and $11 \mathrm{~mm} \mathrm{Hg}$ CPAP or -6 and $-11 \mathrm{~mm} \mathrm{Hg} \mathrm{CNP}$ with initial controls and each other to determine changes that might have occurred.

The mean total number of microspheres injected each time was $506,668 \pm 46,912$ for the CPAP group and 521,981 $\pm 41,193$ for the CNP group. The number of microspheres in reference samples was $1,388 \pm 163$ microspheres for the CPAP group and 1,005 \pm 91 microspheres for the CNP group. The mean percentage of difference in total radioactivity between the duplicate femoral arterial samples was $3.4 \pm 0.72 \%$ for the CPAP group and $4.4 \pm$ $1.0 \%$ for the CNP group. The mean percentage of radioactivity and thus microspheres shunted across the cephalic circulation was $8.1 \pm 1.2 \%$ for the CPAP group and $9.4 \pm 2.0 \%$ for the CNP group.

\section{ENDOTRACHEAL-CPAP GROUP}

The hemodynamic changes observed in the lambs during CPAP breathing are presented in Table 1. Arterial $\mathrm{PO}_{2}, \mathrm{PCO}_{2}$, and $\mathrm{pH}$ were unchanged, as were heart rate and mean left ventricular pressure. Cardiac output decreased $42 \pm 19 \mathrm{ml} / \mathrm{min} \cdot \mathrm{kg}$ during the application of $6 \mathrm{~mm} \mathrm{Hg}$, a fall of $16 \%(P<0.05)$. At $11 \mathrm{~mm} \mathrm{Hg}$, cardiac output fell $47 \pm 28 \mathrm{ml} / \mathrm{min} \cdot \mathrm{kg}$, or $15 \%$, when compared to initial control values $(P<0.05)$. When airway pressure was returned to zero at the end of each study, cardiac output returned to values that were not different from the original control measurements. CVP progressively rose with the application of increasing airway pressure, rising $3.9 \pm 1.4 \mathrm{~mm} \mathrm{Hg}(44 \%)$ during the application of $6 \mathrm{~mm} \mathrm{Hg}$ and $5.0 \pm 1.6 \mathrm{~mm} \mathrm{Hg}$ (77\%) with $11 \mathrm{~mm}$ $\mathrm{Hg}(P<0.05)$. CVP returned to initial control values when airway pressure was removed. JVP responded in a similar fashion; however, the magnitude of change was not as great, increasing $2.4 \pm$ $1.4 \mathrm{~mm} \mathrm{Hg}$ at $6 \mathrm{~mm} \mathrm{Hg}(0.10>\mathrm{p}>0.05)$, and $3.7 \pm 1.1 \mathrm{~mm} \mathrm{Hg}$ at $11 \mathrm{~mm} \mathrm{Hg}(P<0.05)$. JVP also returned to a level similar to the initial control measurement in the final control period.
Blood flows to the organs evaluated during endotracheal-CPAP are presented in Table 2. No significant alteration was observed in blood flows to the spleen, heart, brain, head, or left eye at either level of airway pressure when compared to control values. Although blood flow to the total gastrointestinal tract was unaltered at 6 and $11 \mathrm{~mm} \mathrm{Hg}$ when compared to the initial control, there was a tendency to fall at the higher airway pressure, values being significantly lower than those obtained at $6 \mathrm{~mm} \mathrm{Hg}$. To further evaluate this, blood flows to specific areas of the gastrointestinal tract were analyzed. We found no significant alterations in blood flow to the small bowel, large bowel, or stomach. Renal blood flow also was unaltered at $6 \mathrm{~mm} \mathrm{Hg}$, but fell $0.22 \pm 0.11 \mathrm{ml} / \mathrm{min}$. $\mathrm{g}$ or $14 \%$ during the application of $11 \mathrm{~mm} \mathrm{Hg}$. This decrease in renal blood flow was of borderline statistical significance when compared to the initial control flow $(0.10>P>0.05)$, but was significantly lower than blood flow at $6 \mathrm{~mm} \mathrm{Hg}(P<0.05)$. Hepatic blood flow fell during the application of both 6 and 11 $\mathrm{mm} \mathrm{Hg}$ pressure $(P<0.05)$.

\section{CNP BREATHING}

The cardiovascular changes observed during CNP breathing are presented in Table 3. Arterial $\mathrm{PO}_{2}, \mathrm{PCO}_{2}$, and $\mathrm{pH}$ remained unchanged, as did heart rate, mean left ventricular pressure, and jugualr venous pressure. Cardiac output fell $29 \pm 15$ and $24 \pm 19$ $\mathrm{ml} / \mathrm{min} \cdot \mathrm{kg}$ from initial control values during the application of -6 and $-11 \mathrm{~mm} \mathrm{Hg}$, respectively. This represents a fall of approximately $9 \%$ at both pressure settings, neither of which are statistically significant. When CNP was returned to zero at the end of each study, cardiac output reached values greater than the original control $(P<0.05)$. Central venous pressure progressively fell with higher levels of CNP, decreasing $2.2 \pm 0.7 \mathrm{~mm} \mathrm{Hg}(20 \%)$ at a pressure of $-6 \mathrm{~mm} \mathrm{Hg}, P>0.05$, and $3.1 \pm 0.9 \mathrm{~mm} \mathrm{Hg}(43 \%)$ at $-11 \mathrm{~mm} \mathrm{Hg}, P<0.05$. During the final control period, CVP returned to a level similar to that observed in the initial control period. JVP was $9.1 \pm 0.5 \mathrm{~mm} \mathrm{Hg}$ before the application of the 
neck diaphragm and increased to $15.8 \pm 0.8 \mathrm{~mm} \mathrm{Hg}(43 \%)$ after animals were placed in the CNP box $(P<0.005)$, remaining elevated throughout the course of the experiments.

Regional blood flows measured during CNP breathing are presented in Table 4. No significant change was observed in blood flows to the kidneys, liver, heart, head, brain, left eye, thyroid gland, or adrenals at either pressure setting when compared to control values. Blood flow to total gastrointestinal tract fell 0.33 $\pm 0.10 \mathrm{ml} / \mathrm{min} \cdot \mathrm{g}(25 \%)$ at $-6 \mathrm{~mm} \mathrm{Hg}(P<0.05)$. With the application of $-11 \mathrm{~mm} \mathrm{Hg}$, gastrointestinal blood flow was only $6 \%$ less than control values, a change that was not significant. When blood flows to specific areas of the gastrointestinal tract were analyzed at $-6 \mathrm{~mm} \mathrm{Hg}$, it was found that the reduction in blood flow occurred in the large bowel. With the removal of CNP, gastrointestinal blood flow returned to initial control values. Splenic blood flow progressively fell with greater negative pressures, decreasing $1.78 \pm 0.83 \mathrm{ml} / \mathrm{min} \cdot \mathrm{g}$, or $39 \%$ at $-11 \mathrm{~mm} \mathrm{Hg}$ $(P>0.05)$. Blood flow failed to return to control levels with the removal of CNP; however, the difference was not statistically significant.

\section{ESOPHAGEAL PRESSURES}

In the two lambs in whom intraesophageal pressure was continuously monitored during CPAP, $58 \%$ of the airway pressure was transmitted at $6 \mathrm{mg}$ pressure, whereas 32 and $46 \%$ were transmitted at $11 \mathrm{~mm} \mathrm{Hg}$. Absolute intraesophageal pressure increased $70 \%$ from control pressures with either 6 or $11 \mathrm{~mm} \mathrm{Hg}$ in both animals. In the five lambs studied with continuous monitoring of intraesophageal pressure during CNP breathing, 53 and $74 \%$ of the airway pressure were transmitted at -6 and $-11 \mathrm{~mm} \mathrm{Hg}$, respectively. Absolute intraesophageal pressures fell 56 and $93 \%$ from control pressures with -6 and $-11 \mathrm{~mm} \mathrm{Hg}$, respectively.

\section{DISCUSSION}

Continuous distending airway pressure is commonly used in the treatment of pulmonary and extrapulmonary disorders of the newborn $(4,5,7,10,16,29)$. In view of the potential hemodynamic effects that may result from the use of either CPAP or CNP, we studied the cardiovascular responses to continuous distending alveolar pressure in healthy newborn lambs. In any animal study, it is important to establish and verify that the animal preparation used is as "nearly" physiologic as possible. Inasmuch as we were studying cardiovascular responses, we chose to use low doses of chloral hydrate because it has relatively few known direct effects on the cardiovascular system (12). The stability and validity of our animal model are supported by the observation that the measurements of cardiac output, blood pressure, and arterial blood gases are similar to those reported in chronically instrumented lambs of similar ages (30). Moreover, the values obtained during the final control period are similar to those during the initial control period, with the exception of a significantly higher cardiac output in the CNP group. Other than this alteration, there is no evidence of hemodynamic deterioration during the course of these studies.

A question of the validity of our use of femoral arterial reference samples for the calculations of cardiac output and upper body regional blood flows might be considered in light of the report by Buckberg et al. (2). In that study, they observed significant differences in reference samples obtained from the carotid and femoral arteries, the former usually lower. In contrast, Hales (11) has reported more recently similar values for cardiac output calculated from reference samples obtained from either a common carotid or femoral artery in sheep. This is further supported by our observation in sheep of a lack of difference in arterial reference samples obtained simultaneously from the aortic arch and femoral arteries (24) and more recently in samples obtained from the common carotid or subclavian artery simultaneously with samples from the femoral arteries (C. R. Rosenfeld and J. Watson, unpublished observations).
A fall in cardiac output has been observed in studies of the effects of CPAP in adult humans (17) and animals $(14,15,19,22)$. However, little data are available in the newborn. In a recent study in newborn lambs, a $20 \%$ fall in cardiac output occurred within $15 \mathrm{~min}$ after the application of 6 and $11 \mathrm{~mm} \mathrm{Hg}$ with a head-box apparatus (8). This is similar to that observed in the present study during the application of the same levels of endotracheal-CPAP. The decision to measure cardiac output at $15 \mathrm{~min}$ was based on the common clinical practice of evaluating arterial blood gases in infants 15 to $20 \mathrm{~min}$ after making a change in CPAP. King et al. (18) also found a fall in cardiac output in the adult at $20 \mathrm{~min}$. Inasmuch as the microsphere technique provided a limited number of observations, it is possible that this fall may have been transient.

The reduction in cardiac output that occurs during the application of CPAP in the normal newborn lamb may be explained by postulating changes in lung mechanics. When distending airway pressure is applied in patients in whom the functional residual capacity is either normal or high, it may result in a fall in cardiac output, an increase in intrapulmonary shunting, and the subsequent decline in peripheral oxygen delivery. Our studies in the normal newborn lamb confirm the reduction in cardiac output. Blood volume, venous tone, and myocardial function also are extremely influential in the cardiovascular responses to CPAP. Qvist et al. (22) found that not only did cardiac output fall during positive end expiratory pressure, but that there was no circulatory compensation as long as the pressure was applied unless blood volume was augmented. Thus, in the presence of hypovolemia or shock, states common to the sick infant, the deleterious effects of CPAP on cardiac output may be even more profound.

In studies of CNP in animals, little or no change in cardiac output has been reported (19). We also found that cardiac output does not change significantly. The $9 \%$ fall is less than that seen with the application of CPAP by either head-box (8) or endotracheal tube and is similar to that reported by Krumpe et al. (19).

CVP has been described as rising progressively with increasing levels of applied airway pressure in adults $(15,17)$. In a compliant lung, this is likely the result of overdistention of alveoli and pulmonary vascular compression, both of which might result in a fall in cardiac output and the subsequent decrease in venous return to the right heart. Although CVP has been monitored during CPAP administration, few studies have measured simultaneously both CVP and JVP. In a recent study in newborn lambs, CPAP applied with a head-box apparatus (8) resulted in changes in CVP that were similar to those found in the present study, an increase of 3 to $5 \mathrm{~mm} \mathrm{Hg}$. However, the rise in JVP was substantially greater in both studies and 6-fold greater with head-box CPAP than endotracheal CPAP. It is likely that the higher JVP seen during head-box CPAP reflected the sum of the extrinsic pressure collapsing the neck veins and the increase in CVP, whereas in the present study, the increased JVP is a reflection of only transmitted airway pressure. Hence, the application of CPAP may cause an increase in JVP and CVP, a decrease in venous return to the heart, and the fall in cardiac output noted earlier.

These alterations in venous pressures may be important in the pathophysiology of intracerebral hemorrhage in the preterm infant. Recently, Reynolds et al. (23) have reported that in the fetal lamb the combination of asphyxia with increases in either arterial or venous pressures results in intracerebral hemorrhages and dilation of the thin-walled cerebral veins at sites similar to that found in the preterm infant. The maximum pressure reached in the superior vena cava in their studies was 12 to $13 \mathrm{~mm} \mathrm{Hg}$, a value similar to that found in JVP in the lambs receiving either endotracheal or head-box CPAP (8). It would appear from these studies and others $(1,28)$ that the elevation in JVP and CVP that occurs with continuous distending alveolar pressure could possibly increase the risk of intracerebral hemorrhage in certain infants. More recently, Topper et al. (27) observed that severely ill infants on CPAP or positive end-expiratory pressure developed hyperoxia just before their intracerebral hemorrhage. This sudden change in 
oxygenation may have reflected an improvement in lung compliance, which in turn would have allowed greater transmission of airway pressure.

Although CVP rises with CPAP, it has been observed to fall during CNP (26). In the present study, its fall paralleled the changes in intrapleural pressure. JVP, on the other hand, was not altered. However, the level of JVP during the control period was greater than that observed with endotracheal CPAP and most likely is due to the tight application of the neck diaphragm necessary for the proper function of the ventilator. This is substantiated by the $43 \%$ increase in JVP that was seen after applying the diaphragm. The high JVP maintained during CNP also may be important in the development of intracerebral hemorrhage.

The fall in cardiac output during endotracheal-CPAP was associated with a proportional decrease in renal blood flow at the higher pressure. A similar observation had been made at the same pressure during head-box CPAP (8). Other investigators have reported a deterioration in renal function, as measured by urea clearance and urine output, in both normal and sick adults during continuous airway pressure breathing $(6,20)$. The removal of airway pressure in these studies resulted in rapid improvement of renal function. Our finding of a prompt return of renal blood flow to control values after the removal of CPAP may explain these observations.

Although there was not a statistically significant change in blood flow to the gastrointestinal tract during the application of endotracheal CPAP, there was a tendency to decrease at the higher airway pressure. Similarly, blood flow was found to fall during the application of $-6 \mathrm{~mm} \mathrm{Hg} \mathrm{CNP}$, when cardiac output also had fallen slightly. In this case, the alteration in organ blood flow is greater than the measured fall in cardiac output. In either case, this may be accentuated in the presence of hypovolemia, shock, or asphyxia and may contribute in some infants to the development of ischemic bowel disease, e.g., necrotizing enterocolitis.

In a previous study, we observed that blood flow to the choroidretina fell during head-box CPAP (8). We speculated at that time that this may have been the result of the rise seen in JVP, direct pressure on the eye, and the decrease in cardiac output that occurred. In the present studies, choroid-retinal blood flow tended to fall during both endotracheal CPAP and CNP. These data are supportive of the view that the fall in blood flow observed with head-box CPAP is secondary to the extrinsic pressure applied directly to the eye and the obstructive nature of the rise in JVP. This thesis is supported further by the work of Hayreh and Edwards (13) who made similar observations in arterial perfusion of the monkey eye.

It is apparent from these studies in the normal newborn lamb that the use of continuous distending alveolar pressure in infants with normal or near normal lungs may lead to potentially dangerous situations. Because the newborn lamb may develop hyaline membrane disease when delivered prematurely, further studies should be considered to assess the hemodynamic changes with continuous distending alveolar pressure in animals with hyaline membrane disease.

\section{REFERENCES AND NOTES}

1. Aidinis, S. J., Lafferty, J., and Shapiro, H. M.: Intracranial responses to PEEP. Anesthesiology, 45: 275 (1976)

2. Buckberg, G. D., Luck, J. C., Payne, D. B., Hoffman, J. I. E., Archie, J. P., and Fixler, D. E.: Some sources of error in measuring regional blood flow with radioactive microspheres. J. Appl. Physiol., 31: 598 (1971).

3. Butler, J., and Paley, H. W.: Lung volume and pulmonary circulation. Med. Thorac., 19: 261 (1962)

4. Chernick, V.: Continuous negative chest wall pressure therapy for hyaline membrane disease. Pediatr. Clin. N. Am., 20: 407 (1973).

5. Cotton, R. B., Stahlman, M. T., Kovar, I., and Catterton, W. Z.: Medical management of small preterm infant with symptomatic patent ductus arterio- sus, J. Pediatr., 92: 467 (1978).

6. Drury, D. R., Henry, J. P., and Goodman, J.: The effects of continuous pressure breathing on kidney function. J. Clin. Invest., 26: 495 (1947).

7. Fox, W. W. Bernean, L. S., Downes, J. J., Jr., and Peckham, C. J: The therapeutic application of end-expiratory pressure in the meconium aspiration syndrome. Pediatrics, 66: 214 (1975).

8. Gabriele, G. Rosenfeld, C. R. Fixler, D. E, and Wheeler, I. M. The effects of continuous airway pressure breathing with the head-box on regional blood flow. Pediatrics, 59: 858 (1977).

9. Gregory, G. A. Edmunds, L. H., Kitterman, J. A., Phibbs, R. H., and Tooley, W. H.: Continuous positive airway pressure and pulmonary and circulatory function after cardiac surgery in infants less than three months of age. Anesthesiology, 43: 426 (1975).

10. Gregory, G. A., Kitterman, J. A., Phibbs, R. H., Tooley, W. H., and Hamilton, W. K.: Treatment of the idiopathic respiratory distress syndrome with continuous positive airway pressure. N. Engl. J. Med., 284: 1333 (1971).

11. Hales, J. R. S.: Radioactive microsphere measurement of cardiac output and regional tissue blood flow in the sheep. Pflugers Arch. Eur. J. Physiol., 344: 199 (1973).

12. Harvey, S. C. : Hypnotics and sedatives - miscellaneous agents. In: L. S. Goodman and A. Gilman: The Pharmacological Basis of Therapeutics. pp. 127-129 (MacMillan Publishing Co., Inc., New York, 1975).

13. Hayreh, S. S., and Edwards, J.: Ophthalmic arterial and venous pressures, effects of acute intracranial hypertension. Br. J. Ophthaimol., 55: 649 (1971).

14. Holt, J. P.: The effects of positive and negative intrathoracic pressure on cardiac output and venous pressures in the dog. Am. J. Physiol., 142: 594 (1944).

15. Hunt, C. E., Matalon, S., Neal, W. A., Wangesteen, O. D., and Leonard, A. S. Cardiorespiratory responses to positive end-expiratory pressure (PEEP). Pediatr. Res., 8: 468 (1974)

16. Kattwinkel, J., Nearman, H. S., Farranoff, A. A., Katona, P. G., and Klaus, M. H.: Apnea of prematurity, comparative therapeutic effects of cutaneous stimulation and nasal continuous positive airway pressure. J. Pediatr., 86: 588 (1975).

17. Kilburn, K. H., and Sieker, H. O.: Hemodynamic effects of continuous positive and negative pressure breathing in normal man. Circ. Res., 8: 660 (1960).

18. King, E. G., Jones, R. L., and Patakas, D. A.: Evaluation of positive endrespiratory pressure therapy in the adult respiratory distress syndrome. Can. Anaesth. Soc. J., 20: 546 (1973).

19. Krumpe, P. E., Zidulka, A., Urbanetti, J., and Anthronisen, N. R.: Comparison of the effects of continuous negative intrathoracic chest pressure and positive end-expiratory pressure on cardiac index in dogs. Am. Rev. Respir. Dis., 115: 39 (1977).

20. Kumar, A., Falke, K. J., Geffin, B., Aldridge, C. F., Larer, M. B., Lowenstein, E., and Pontoppidan, H.: Continuous positive pressure ventilation in acute respiratory failure. N. Engl. J. Med., 283: 1430 (1970)

21. Lenfant, C., and Howell, B. J.: Cardiovascular adjustments in dogs during continuous pressure breathing. J. Appl. Physiol., 15: 425 (1960).

22. Qvist, J., Pontoppidan, H., Wilson, R. S., Lowenstein, E., and Laver, M. B.: Hemodynamic responses to mechanical ventilation with PEEP: The effects of hypervolemia. Anesthesiology, 42: 45 (1975).

23. Reynolds, M. L., Evans, C. A. N., Reynolds, E. O. R., Sanders, N. R., Durbin, G. M., and Wigglesworth, J. S.: Intracranial hemorrhage in the preterm sheep fetus. Early Hum. Dev., 3: 163 (1979)

24. Rosenfeld, C. R.: Distribution of cardiac output in ovine pregnancy. Am. J. Physiol., 232: H231 (1977).

25. Rosenfeld, C. R., Killam, A. P., Battaglia, F. C., Makowski, E. L., Meschia, G.: Effect of estradiol-17 $\beta$ on the magnitude and distribution of uterine blood flow in nonpregnant oophorectomized ewes. Pediatr. Res., 7: 139 (1973).

26. Ting, E. Y., Hong, K., and Rahn, H.: Cardiovascular responses of man during negative pressure breathing. J. Appl. Physiol., 25: 557 (1960).

27. Topper, W., Buckwald, S., and Egan, E.: The interrelationship of intraventricular hemorrhage (IVH) with acid-base and respiratory status of preterm infants. Pediatr. Res. (Abstract), 13: 508 (1979).

28. Vent, P., Andre, M., and Sibout, M.: Continuous positive airway pressure and hydrocephalus. Lancet, 2: 319 (1973).

29. Vidyasagar, D.: Physiological basis and clinical implications of continuous negative chest wall pressure in hyaline membrane disease. Int. Anesthesiol. Clin., 12: 153 (1974).

30. Woods, J. R., Jr., Davidavino, A., Brinkman, C. R., III, Nuwayhid, B., and Assali, N. S.: Cardiac output changes during neonatal growth. Am. J. Physiol., 235: H520 (1978)

31. Yu, V. Y. H., and Rolfe, P.: Effect of continuous positive airway pressure breathing on cardiorespiratory function in infants with respiratory distress syndrome. Acta Pediatr. Scand., 66: 59 (1977).

32. Requests for reprints should be addressed to: Charles R. Rosenfeld, M.D., Department of Pediatrics, Southwestern Medical School, 5323 Harry Hines Boulevard, Dallas, TX 75235 (USA).

33. This research was supported in part by NIH grant HD08783 and supported in part by American Heart Association Grant 73667

34. Received for publication January 22, 1980.

35. Accepted for publication September 16, 1980 